\title{
The Metabolism of 1,2-Propanediol by the Facultative Methylotroph Pseudomonas AM1
}

\author{
By J. A. BOLBOT $\dagger$ AND C. ANTHONY* \\ Department of Biochemistry, School of Biochemical and Physiological Sciences, \\ University of Southampton, Southampton SO9 $3 T U$
}

(Received 31 January 1980; revised 28 March 1980)

\begin{abstract}
Pseudomonas AM1 grows on 1,2-propanediol with a mean doubling time of $7 \mathrm{~h}$. The growth responses of a wide range of mutants suggest that propanediol is assimilated into cell material by way of pyruvate and acetyl-CoA. The normal enzymes for the initial metabolism of propanediol [NAD(P)+-linked dehydrogenase, propanediol oxidase and propanediol dehydratase] were absent. The initial oxidation of propanediol was catalysed by methanol dehydrogenase but only in the presence of a large molecular weight (possibly protein) stimulatory factor that seemed to change the substrate specificity of the enzyme; the product of the oxidation was lactate.
\end{abstract}

\section{INTRODUCTION}

Pseudomonas AM1 is a pink facultative methylotroph unable to grow on methane but able to grow on methanol and on a range of multicarbon compounds. The pathway of assimilation of $C_{2}$ and $C_{3}$ compounds is unusual; these compounds are assimilated exclusively by way of acetyl-CoA in the absence of a complete glyoxylate cycle (Anthony, $1975 a$ ). In a survey of potential growth substrates likely to be assimilated by the same route, it was found that Pseudomonas AM1 grew well on 1,2-propanediol. This property has previously been observed with other facultative methylotrophs (Toraya et al., 1976; Nishio et al., 1978; Sato, 1978). A preliminary survey of growth responses of mutants of Pseudomonas AM1 suggested that propanediol may be oxidized and assimilated in a novel manner in this facultative methylotroph and the results presented below confirm this. Propanediol appears to be oxidized by way of methanol dehydrogenase (EC 1.1.99.8) but only in the presence of a stimulatory factor that changes its substrate specificity. The assimilation pathway appears to be by way of pyruvate, acetyl-CoA and the unconventional route for acetyl-CoA assimilation in Pseudomonas AM1.

\section{METHODS}

Growth media and maintenance of cultures. The growth medium was based on that of Maclennan et al. (1971) and has been described previously (Bolbot \& Anthony, 1980). The final concentration of carbon source in the medium was $0.5 \%(\mathrm{v} / \mathrm{v})$ for methanol and 1,2-propanediol and $0.2(\mathrm{w} / \mathrm{v})$ for other substrates, unless otherwise stated. Stock cultures were maintained on methylamine- or succinate-agar slopes at $4{ }^{\circ} \mathrm{C}$.

Growth and harvesting of cultures. Cultures $(500 \mathrm{ml})$ were grown in shaken 21 baffled conical flasks at $30^{\circ} \mathrm{C}$ from a $5 \%$ inoculum of bacteria grown on the same carbon source. Growth responses of mutants were checked before harvesting to ensure that contaminants or spontaneous revertants were absent. Bacteria were harvested in the late-exponential phase of growth by centrifugation at $4000 \mathrm{~g}$ for $15 \mathrm{~min}$. Before use, the bacteria were washed twice and resuspended in $20 \mathrm{~mm}$-sodium/potassium phosphate buffer, pH 7.0.

$\uparrow$ Present address: Department of Chemistry, University of Texas at Arlington, Texas 76019, U.S.A. 
Measurement of oxygen uptake by bacterial suspensions. This was measured using a Rank $\mathrm{O}_{2}$ electrode at $30^{\circ} \mathrm{C}$. The incubation vessel contained in $2 \mathrm{ml}, 40 \mu \mathrm{mol}$ sodium phosphate buffer, $\mathrm{pH} 7.0$ and sufficient

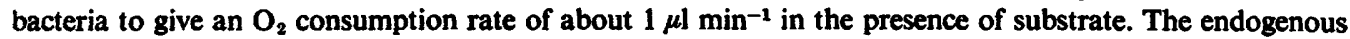
rate of $\mathrm{O}_{2}$ consumption was measured for $5 \mathrm{~min}$ before injection of substrates which were used at a final concentration of $7.5 \mathrm{mM}$. Rates of $\mathrm{O}_{2}$ uptake were calculated assuming that $0.45 \mu \mathrm{mol} \mathrm{O}_{2}$ is dissolved in $2 \mathrm{ml}$ buffer at $30^{\circ} \mathrm{C}$.

Preparation of cell-free extracts. Suspensions of bacteria $\left(0.3 \mathrm{~g}\right.$ wet wt $\left.\mathrm{ml}^{-1}\right)$ were disrupted at $2{ }^{\circ} \mathrm{C}$ for $3 \times 2$ min periods (separated by $3 \mathrm{~min}$ cooling periods) in a $100 \mathrm{~W}$ MSE ultrasonic disintegrator at $20 \mathrm{kHz}$ using a probe tip of $1.9 \mathrm{~cm}$ diam. The sonicate was centrifuged at $2{ }^{\circ} \mathrm{C}$ at $3000 \mathrm{~g}$ for $15 \mathrm{~min}$ to remove unbroken bacteria before centrifuging at $40000 \mathrm{~g}$ for $1 \mathrm{~h}$. The supernatant after this centrifugation is referred to as the crude extract. Crude extracts of mutant PCT29 were prepared in the same way.

Mutant strains of Pseudomonas AM1. These mutants are described in detail elsewhere: mutant PCT29 (Dunstan et al., 1972a); PCT48 (Dunstan et al., 1972b); PCT57 (Dunstan et al., 1972b; Salem et al., 1974; Cox \& Quayle, 1976a; Bolbot \& Anthony, 1980); PCT76 (Anthony, 1975b); ICT51 and ICT54 (Taylor \& Anthony, 1976; Cox \& Quayle, 1976a); JAB10, JAB21, JAB30 and JAB40 (Bolbot \& Anthony, 1980). Mutants PCT 29 and PCT76 were grown on a mixture of succinate $(0.2 \%)$, methanol $(0.2 \%)$ and methylamine $(0.2 \%)$.

Amino acid analysis of culture medium. This was done as described by Bolbot \& Anthony (1980).

Methanol dehydrogenase and 1,2-propanediol dehydrogenase activities. These phenazine methosulpate (PMS)coupled dehydrogenases were assayed using the system of Anthony \& Zatman (1967a) with the decreased PMS concentration suggested by Bamforth \& Quayle (1978) in an $\mathrm{O}_{2}$ electrode. Reaction mixtures contained ( $\mu \mathrm{mol}$, in $2 \mathrm{ml}$ ); Tris/HCl, pH 9.0, 200; $\mathrm{NH}_{4} \mathrm{Cl}, 30 ; \mathrm{PMS}, 1 \cdot 1$; methanol, 15, or 1,2-propanediol, 60. Assays were started by adding substrate or enzyme. One unit (U) of enzyme activity is defined as that amount of enzyme catalysing the reduction of $1 \mu \mathrm{mol}$ PMS min ${ }^{-1}$; because propanediol is oxidized in two steps to lactate (see below) this probably corresponds to $1 \mu \mathrm{mol}$ propanediol but $2 \mu \mathrm{mol}$ methanol if methanol is oxidized only as far as formaldehyde or $1 \mu \mathrm{mol}$ methanol if this is oxidized to formate.

Purification of methanol dehydrogenase from Pseudomonas AM1. This was achieved using the methods described previously for purification of the dehydrogenase from Pseudomonas M27 (Anthony \& Zatman, 1967a). It was completely pure as shown by its spectrum and by isoelectric focusing and sodium dodecyl sulphate-polyacrylamide gel electrophoresis. The enzyme was identical when prepared from cells grown on methanol or on 1,2-propanediol.

Assay of $N A D(P)^{+}$-linked 1,2-propanediol dehydrogenase and 1,2-propanediol dehydratase. Propanediol dehydrogenase was assayed in the presence of phenylhydrazine in an attempt to trap aldehyde or ketone product. The reaction mixture contained $(\mu \mathrm{mol}$, in $1 \mathrm{ml})$ : potassium phosphate buffer, pH 7.0, 100; phenylhydrazine hydrochloride, 5 ; NAD(P) ${ }^{+}, 2 ; 1,2$-propanediol, 10. Changes in absorption at $340 \mathrm{~nm}$ were recorded. In attempts to assay the enzyme in the reverse direction, similar assays were performed at pH 5.0 (sodium acetate buffer) or 7.0 in the absence of phenylhydrazine and using hydroxyacetone (acetol) as substrate and NAD(P)H (0.15 $\mu \mathrm{mol})$ as reductant.

Propanediol dehydratase was assayed by the method of Toraya et al. (1979).

Partial purification of '1,2-propanediol dehydrogenase'. Crude extracts (described above) were passed through a column $(2.5 \times 10 \mathrm{~cm})$ of DEAE-cellulose (Whatman DE52) equilibrated with $20 \mathrm{mM}$-Tris $/ \mathrm{HCl}$, $\mathrm{pH}$ 8.0. The material passing through the column was then purified by gel filtration at $2{ }^{\circ} \mathrm{C}$ using an upward flow column $(1.5 \times 70 \mathrm{~cm}$ ) of Sephadex G-75 (Superfine grade) equilibrated in the same buffer; a $4.3 \mathrm{ml}$ sample was used and $3 \mathrm{ml}$ fractions were collected. The enzyme was concentrated under $\mathrm{N}_{2}$ before and after the gel filtration in a pressure cell with an Ulvac ultrafiltration membrane (mol. wt cut-off, 10000). The material produced by this method is referred to as partially purified 'propanediol dehydrogenase'.

Identification of the product of '1,2-propanediol dehydrogenase' activity. This was possible because of the help of Mrs K. Ballard and Dr D. L. Corina of the Biochemistry Department, Southampton University. 1,2-Propanediol was measured by gas-liquid chromatography (g.l.c.) using a column of $25 \%(w / w)$ DEGA-phosphate on 100 to 120 mesh Chromosorb $P$ at $170^{\circ} \mathrm{C}$ in a Pye Unicam gas chromatograph. The following compounds were analysed without prior modification: methanol, ethanol, hydroxyacetone (acetol), formaldehyde, acetaldehyde, propionaldehyde, pyruvaldehyde, formic acid, acetic acid, propionic acid. Two g.l.c. columns were needed for detection of all these standards: $10 \%$ (w/w) Carbowax 1540 on Tefion (30 to 60 mesh) at $70{ }^{\circ} \mathrm{C} ; 140 \%$ and $10 \%$ DEGA-phosphate on Diatomite CQ (100 to 120 mesh) at $130^{\circ} \mathrm{C}$ and $170^{\circ} \mathrm{C}$. Trimethylsilyl (TMS) derivatives were prepared after freeze-drying by the method of Bentley et al. (1963); TMS derivatives of formate, acetate, pyruvate, lactate and 1,2-propanediol were used as standards on a g.l.c. column of OV1 at $80^{\circ} \mathrm{C}$. L-Lactate was measured with L-lactate dehydrogenase (pig heart, from Boehringer) by the method of Bergmeyer (1974). 


\section{RESULTS}

\section{Growth of Pseudomonas AM1 on 1,2-propanediol}

In a screening of carbon compounds as potential growth substrates for Pseudomonas AM1, it was found that 1,2-propanediol was a good source of carbon and energy but that no growth was obtained on the following compounds $(0.5 \%, \mathrm{w} / \mathrm{v})$ : ethanediol, glycerol, glycerate, 1-propanol, 1,3-propanediol, 2-propanol, propionate, acetone, tartrate, 2hydroxybutyrate, 2-oxobutyrate, crotonate, homoserine, threonine, 1,2-butanediol, 1,3-butanediol, 1,4-butanediol, 2,3-butanediol 1,2,4-butanetriol, 2-hydroxyglutarate and citramalate.

The doubling time of bacteria on $65 \mathrm{~mm}$-1,2-propanediol was $7 \mathrm{~h}$ and the extent of growth was similar to that obtained on methanol. After growth was complete it was shown that sarcosine had accumulated $(150 \mu \mathrm{M})$ but the significance of this observation remains obscure. The pink facultative methylotrophs Pseudomonas M27 and Pseudomonas extorquens also grew on 1,2-propanediol but Methylophilus methylotrophus, an obligate methylotroph, failed to grow on this substrate.

\section{Growth response of mutants of Pseudomonas AM1 to 1,2-propanediol}

Mutants lacking malyl-CoA lyase (mutant PCT57) and acetyl-CoA synthetase (ICT54) showed normal growth on propanediol as did mutant ICT51 which has a hydrolase having a greatly increased $K_{\mathrm{m}}$ for its substrate malyl-CoA (Cox \& Quayle, 1976a).

Mutants lacking 2-oxoglutarate dehydrogenase (JAB10, JAB30) and pyruvate debydrogenase (JAB21), required for pyruvate oxidation, failed to grow on pyruvate or propanediol.

Mutants unable to assimilate acetyl-CoA in the absence of added glyoxylate (PCT48 and JAB40) only grew on propanediol when the growth medium was supplemented with 5 mM-glyoxylate. Mutant JAB40 also failed to grow on pyruvate unless supplemented with glyoxylate.

A mutant having low levels of methanol dehydrogenase (PCT29) grew at a very low rate and a mutant lacking cytochrome $c$ (PCT76) failed to grow on propanediol.

These results suggest that pyruvate is an intermediate in the assimilation of propanediol. This conclusion is consistent with the observation that the rate of pyruvate oxidation was much higher in propanediol-grown bacteria than in methanol-grown bacteria; the $Q_{0}$, for pyruvate oxidation by propanediol-grown bacteria was $43 \mu \mathrm{l} \mathrm{O}$ consumed (mg dry wt) $^{-1}$ $\mathrm{h}^{-1}$ and the specific activity of pyruvate dehydrogenase in extracts derived from these bacteria was $47 \mathrm{nmol} \mathrm{min}^{-1}$ (mg protein)-1; these values compare with a $Q_{\mathrm{O}_{2}}$ of $8 \mu \mathrm{l} \mathrm{O}_{2}$ (mg dry wt) $)^{-1} \mathrm{~h}^{-1}$ and a specific activity for pyruvate dehydrogenase of $4 \mathrm{nmol} \mathrm{min-1}(\mathrm{mg}$ protein $)^{-1}$ in methanol-grown bacteria and their extracts. Pseudomonas AM1 is able to grow on L-lactate and whole cells were always able to oxidize this substrate, whose oxidation is catalysed by an NAD+-coupled L-lactate dehydrogenase (Taylor \& Anthony, 1976). This enzyme was not markedly increased in activity during growth on 1,2-propanediol.

\section{Involvement of methanol dehydrogenase in the oxidation of 1,2-propanediol by Pseudomonas AM1}

Crude extracts of propanediol-grown Pseudomonas AM1 contained no enzyme catalysing the reduction of $\mathrm{NAD}(\mathrm{P})^{+}$in the presence of 1,2-propanediol and they catalysed no $\mathrm{O}_{2^{-}}$ dependent oxidation of propanediol nor any dehydration of propanediol to propionaldehyde (catalysed by a dehydratase). Furthermore, the slow growth of mutant PCT29, having a low activity of methanol dehydrogenase, suggested that this enzyme may be involved in propanediol oxidation. The failure of mutant PCT76 (lacking cytochrome $c$ ) to grow on propanediol is consistent with this conclusion because cytochrome $c$ appears to be essential only for the oxidation of methylamine and of alcohols by way of methanol 
dehydrogenase (Anthony, 1975b). This conclusion was unexpected because pure methanol dehydrogenase from Pseudomonas M27 does not oxidize primary alcohols with more than one substituent on the C-2 carbon atom and thus it does not oxidize 1,2-propanediol (Anthony \& Zatman, 1965); the failure to oxidize propanediol was confirmed using methanol dehydrogenase purified from Pseudomonas AM1 by the method of Anthony \& Zatman (1967a).

In contrast to this result with pure enzyme, propanediol $(30 \mathrm{~mm})$ was oxidized by crude extracts of propanediol-grown wild-type bacteria when it replaced methanol in the standard dehydrogenase assay system (see Methods). Furthermore, when mutant PCT29, having a low methanol dehydrogenase activity, was grown on a mixture of methanol plus methylamine plus succinate, it oxidized methanol and propanediol at only $10 \%$ of the rate measured in wild-type bacteria, and the specific activity of methanol dehydrogenase assayed with methanol or propanediol in extracts of these bacteria was about $5 \%$ of that measured in extracts of wild-type bacteria.

The relationship between methanol oxidation and propanediol oxidation was confirmed by measuring rates of oxidation of these substrates by whole cells and by extracts (using the methanol dehydrogenase assay system) of bacteria grown on a range of carbon sources including methanol, propanediol, 3-hydroxybutyrate, pyruvate and succinate. The ratio of $Q_{\mathrm{O}_{2}}$ for methanol to $Q_{\mathrm{O}_{2}}$ for propanediol was always between 5.9 and 6.4, while the ratio of specific activities of methanol dehydrogenase to 'propanediol dehydrogenase' was always between $2 \cdot 7$ and $3 \cdot 5$.

\section{Properties of '1,2-propanediol dehydrogenase'}

For convenience, the dehydrogenase activity measured in the methanol dehydrogenase assay system containing $30 \mathrm{~mm}-1,2$-propanediol instead of methanol is called 'propanediol dehydrogenase' activity. The properties described here were determined with crude extracts (see Methods). The results were the same when extract was prepared from bacteria grown on methanol or 1,2-propanediol. Prolonged dialysis of crude extracts (for $50 \mathrm{~h}$ at $4^{\circ} \mathrm{C}$ against $5000 \mathrm{vol} .10 \mathrm{~mm}$-potassium phosphate buffer, $\mathrm{pH} \mathrm{7.0)}$ led to complete loss of both methanol dehydrogenase and 'propanediol dehydrogenase' activities and these were restored to $80 \%$ of the original activity by including $\mathrm{NH}_{4} \mathrm{Cl}$ in the assay system, as previously found for methanol dehydrogenase (Anthony \& Zatman, 1964).

Doubling the phenazine methosulphate concentration (to $1.1 \mathrm{~mm}$ ) had little effect on either dehydrogenase activity whereas halving the concentration decreased both activities to about $30 \%$. Neither activity was diminished by storage at $4{ }^{\circ} \mathrm{C}$ for $50 \mathrm{~h}$ or at $20^{\circ} \mathrm{C}$ for $16 \mathrm{~h}$ and both activities were present exclusively in the supernatant fluid after centrifugation for $2 \mathrm{~h}$ at $40000 \mathrm{~g}$ at $2{ }^{\circ} \mathrm{C}$. When both methanol $(7.5 \mathrm{~mm})$ and propanediol $(30 \mathrm{~mm})$ were present together in the assay system the rates of oxygen consumption in the presence of the two substrates were not additive; the rate was about $85 \%$ of that measured with methanol alone. The apparent $K_{\mathrm{m}}$ for propanediol was $33 \mathrm{mM}$ which is about 1500 times that measured for methanol in the same assay system (Anthony \& Zatman, 1964). The rate of propanediol oxidation with the usual concentration used ( $30 \mathrm{~mm}$ ) was about $30 \%$ of that with methanol and so the relative $V_{\max }$ value would be about $60 \%$ of that with methanol as substrate.

The $\mathrm{pH}$ optimum with propanediol (in $\mathrm{Tris} / \mathrm{HCl}$ and glycine/ $\mathrm{NaOH}$ buffers) was between 8.5 and 9.0 whereas that with methanol was at least 9.7 ; the assay system cannot be used at $\mathrm{pH}$ values greater than $\mathbf{1 0 \cdot 0}$.

\section{Requirement for a stimulatory factor for 'propanediol dehydrogenase' activity}

The results presented above suggest strongly that methanol dehydrogenase is involved in 'propanediol dehydrogenase' activity but that a stimulatory factor, lost on purification of the enzyme, may also be required; the results below confirm that this is so. 


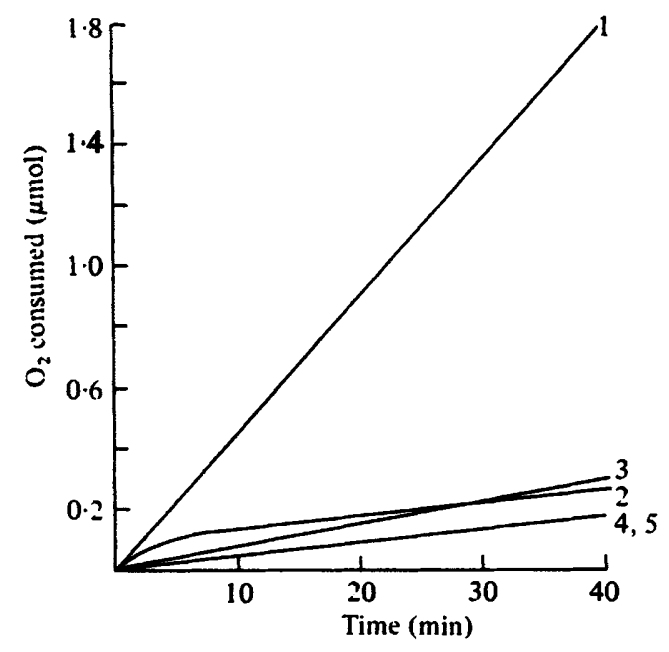

Fig. 1. Effect of crude extract of mutant PCT29 on the '1,2-propanediol dehydrogenase' activity of pure methanol dehydrogenase. Oxygen uptake was measured in the standard dehydrogenase assay system. (1) Pure methanol dehydrogenase $(450 \mathrm{mU})$ plus crude extract of mutant PCT29 (0.75 mg protein) plus $30 \mathrm{~mm}$-1,2-propanediol; (2) pure methanol dehydrogenase (450 mU) plus 30 mM-1,2-propanediol; (3) crude extract of PCT29 (0.75 mg protein) plus $30 \mathrm{~mm}-1$,2-propanediol;

(4) pure methanol dehydrogenase plus PCT29 extract; (5) PCT29 extract.

The rate of oxidation of propanediol by pure methanol dehydrogenase was very low (Fig. 1), but addition of an extract of mutant PCT29 (with very low methanol dehydrogenase activity) promoted oxidation of propanediol suggesting that crude extracts have a factor able to confer 'propanediol dehydrogenase' activity on methanol dehydrogenase. The PCT29 extract lost all its activity on heating at $70{ }^{\circ} \mathrm{C}$ for $3 \mathrm{~min}$ but only $10 \%$ was lost after dialysis for $24 \mathrm{~h}$ at $2^{\circ} \mathrm{C}$ against 2000 vol. $10 \mathrm{~mm}$-potassium phosphate buffer, pH 7.0. 'Propanediol dehydrogenase' activity was lost when the pH of crude extracts was lowered to $\mathrm{pH} \mathrm{4.0;}$; because methanol dehydrogenase is stable at this $\mathrm{pH}$ (Anthony \& Zatman, $1964,1967 \mathrm{~b}$ ), this result suggests that the 'propanediol dehydrogenase' stimulatory factor is sensitive to low pH values. When crude extracts of propanediol-grown bacteria were passed through DEAE-cellulose equilibrated with $20 \mathrm{mM}$-Tris/ $\mathrm{HCl}$ buffer, $\mathrm{pH} 8 \cdot 0$, neither the methanol dehydrogenase nor the 'propanediol dehydrogenase' bound to the ionexchange cellulose indicating that the isoelectric point of the stimulatory factor was high or that it was tightly bound to the methanol dehydrogenase. This process purified both the methanol dehydrogenase and 'propanediol dehydrogenase' about fourfold in $90 \%$ yield (see below). When the material eluted from the DEAE-cellulose was passed through Sephadex G-75, both methanol dehydrogenase and 'propanediol dehydrogenase' were eluted in the void volume indicating that the 'propanediol dehydrogenase' stimulatory factor has a molecular weight of at least 30000 .

The above results indicate that a stimulatory factor is required to confer on methanol dehydrogenase the property of a propanediol dehydrogenase and that this factor has a high molecular weight, a high isoelectric point and is sensitive to high temperature and low $\mathrm{pH}$ values. These properties suggest that it may be a protein, but no direct evidence is yet available.

\section{Partial purification of '1,2-propanediol dehydrogenase'}

In order to identify the product of ' propanediol dehydrogenase' activity and to investigate the substrate specificity of the dehydrogenase it was necessary to purify the enzyme(s) responsible. Because pure stimulatory factor was not available it was necessary to use a 
method that would co-purify methanol dehydrogenase and the factor conferring 'propanediol dehydrogenase' activity on this enzyme.

The procedure is described fully in Methods: crude extract was passed through DEAEcellulose and the eluate was then passed through a column of Sephadex G-75. The ratio of methanol dehydrogenase activity to 'propanediol dehydrogenase' activity was almost the same in all fractions collected from the columns (2.73 to 2.93$)$. The overall purification was about fivefold. The absorption spectrum showed that the partially purified preparation contained no cytochrome $c$; it had peaks at $280 \mathrm{~nm}$ and a peak at $345 \mathrm{~nm}$ due to methanol dehydrogenase (Anthony \& Zatman, $1967 b$ ); the $A_{345} / A_{280}$ ratio of the partially purified material was $46 \%$ of that of the pure methanol dehydrogenase. This partially purified 'propanediol dehydrogenase' was used in the experiments described below.

\section{Substrate specificity of the partially purified '1,2-propanediol dehydrogenase'}

This was determined in the standard methanol dehydrogenase assay system using $30 \mathrm{~mm}$ alcohols and $0 \cdot 1$ to $7.0 \mathrm{~mm}$ aldehydes instead of methanol. The substrate specificity was the same as that previously described for pure methanol dehydrogenase (Anthony \& Zatman, 1965) except that 1,2-propanediol, 1,2-butanediol, and glycerol and glycerate were also oxidized (at 30, 30, 6 and $3 \%$, respectively, of the rates measured with methanol). Hydroxyacetone (acetol), 2,3-butanediol, acetaldehyde, glycolaldehyde and propionaldehyde were not oxidized. The results suggest that 'propanediol dehydrogenase' is active with substrates conforming to the general formula $\mathrm{RCHOH} . \mathrm{CH}_{2} \mathrm{OH}$, but the low rates measured with glycerol and glycerate suggest that substitution at the carbon atom adjacent to the diol group greatly reduced the rate at which a compound was oxidized; this may be due to a lower $V_{\max }$ or to a higher $K_{\mathrm{m}}$ value, parameters not determined for these substrates.

\section{Product of '1,2-propanediol dehydrogenase' activity}

Potential products of 'propanediol dehydrogenase' activity were measured after incubation of partially purified 'propanediol dehydrogenase' for $1.5 \mathrm{~h}$ in the standard assay system containing $30 \mathrm{~mm}-1,2-$ propanediol. The following compounds were not detected by g.l.c.: methanol, ethanol, hydroxyacetone (acetol), formaldehyde, acetaldehyde propionaldehyde, methylglyoxal, formic acid, acetic acid, propionic acid or pyruvic acid. Lactic acid, as the trimethylsilyl (TMS) derivative, was the only product detected. When enzyme was omitted from the reaction mixture the only TMS derivative measured was TMS-1,2-propanediol and no TMS derivative was detected in incubation mixtures from which substrate (1,2-propanediol) was omitted. Comparison of the areas beneath the g.l.c. peaks for TMS-propanediol and TMS-lactate showed that about $50 \%$ of the propanediol consumed had been converted to lactate. The concentration of lactate determined by g.l.c. was identical to that determined using a lactate assay based on enzymic determination of L-lactate suggesting that the substrate for oxidation is the L-isomer of 1,2-propanediol. The identity of TMS-lactate was confirmed by g.l.c./mass spectrometry. During production of $29 \mu \mathrm{mol} \mathrm{L}$-lactate, $30 \mu \mathrm{mol} 1$,2-propanediol disappeared from the reaction mixture and $25 \mu \mathrm{mol} \mathrm{O}_{2}$ was consumed. These results show that the equivalent of two oxidation steps occur during oxidation of propanediol in the methanol dehydrogenase assay system giving the following stoicheiometry:

$$
\text { L-1,2-Propanediol }+\mathrm{O}_{2} \longrightarrow \text { L-Lactate }+\mathrm{H}_{2} \mathrm{O}
$$

If the product of the first oxidation step is lactaldehyde then it appears to remain tightly bound to the enzyme because none was detected in the reaction products.

Lactate was also the only product, determined by g.l.c., during the oxidation of 1,2propanediol by suspensions of methanol-grown Methylophilus methylotrophus, an obligate methylotroph unable to grow on propanediol. The relative rates of oxidation of methanol and propanediol were 5:1 as found with whole cells of Pseudomonas AM1. This suggests 


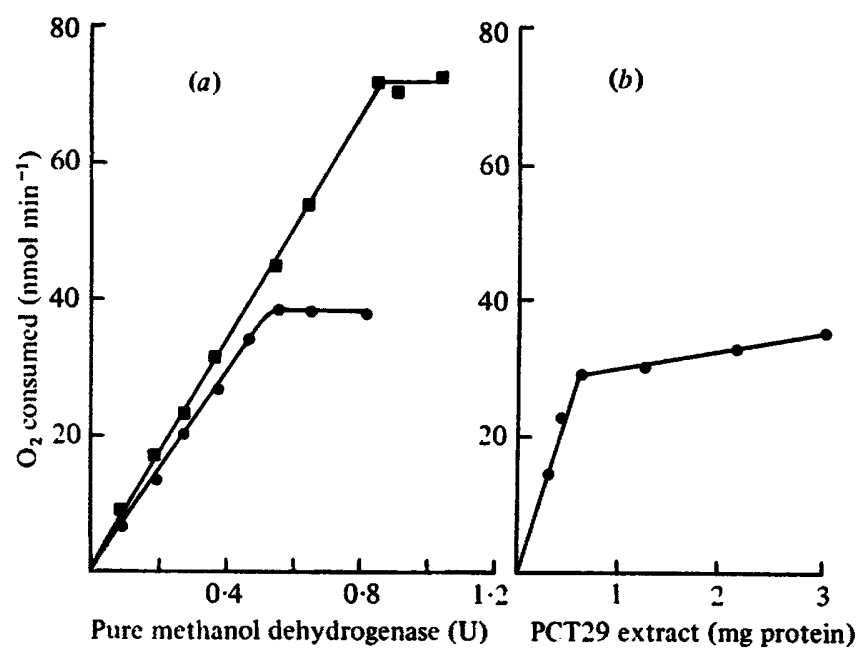

Fig. 2. Dependence of '1,2-propanediol dehydrogenase' activity on methanol dehydrogenase and a factor present in crude extracts of mutant PCT29. Enzyme activity was measured in the standard dehydrogenase assay system containing $30 \mathrm{~mm}$-1,2-propanediol as substrate. (a) The concentration of pure methanol dehydrogenase was varied while PCT29 extract was kept constant at $0.75 \mathrm{mg}$ protein (O) or $1.5 \mathrm{mg}$ protein $(\square)$. (b) The concentration of PCT29 extract was varied while pure methanol dehydrogenase was kept constant at $360 \mathrm{mU}$.

that the ability of methylotrophic bacteria to oxidize 1,2-propanediol depends on the presence of methanol dehydrogenase rather than on an enzyme specifically involved in growth on propanediol.

\section{Transitory oxidation of 1,2-propanediol by pure methanol dehydrogenase}

As stated above, pure methanol dehydrogenase does not oxidize 1,2-propanediol to any extent. However, using $90 \mathrm{~mm}$-propanediol instead of methanol in the standard assay system containing $40 \mathrm{mU}$ of pure methanol dehydrogenase, there was a transitory oxidation at a rate which was initially $30 \%$ of that with methanol and which lasted about $8 \mathrm{~min}$; ammonia, the activator of methanol dehydrogenase, was required for this activity. When a further similar amount of methanol dehydrogenase was then added another similar transitory oxidation was observed, but addition of further propanediol led to no further oxygen consumption. When methanol was added after the $8 \mathrm{~min}$ incubation in the presence of propanediol this was oxidized at only $20 \%$ of the rate measured after 8 min incubation in the absence of propanediol. The rate and extent of the transitory oxidation and the subsequent inhibition of methanol oxidation was roughly proportional to the amount of propanediol present in the preincubation mixture.

\section{Reaction of '1,2-propanediol dehydrogenase' stimulatory factor with pure methanol dehydrogenase}

'Propanediol dehydrogenase' activity was measured in the usual assay system with various amounts of pure methanol dehydrogenase and of crude extract of mutant PCT29; the net 'propanediol dehydrogenase' activity was calculated by subtracting the low rate measured with PCT29 extract alone. The results in Fig. 2 show that for a given amount of PCT29 extract $(0.75 \mathrm{mg}$ protein) the rate of propanediol oxidation was proportional to the methanol dehydrogenase concentration up to a critical value $(450 \mathrm{mU})$ above which further increases in concentration had little effect; when the amount of PCT29 extract was doubled (to $1.5 \mathrm{mg}$ protein) the limiting concentration of methanol dehydrogenase was also doubled. In an analogous experiment in which the methanol dehydrogenase concentration was 


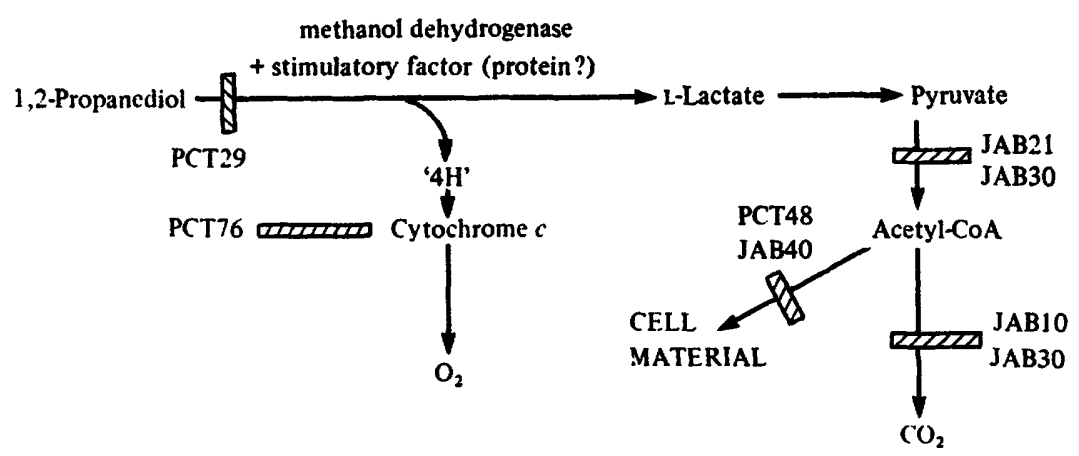

Fig. 3. Proposed pathway for the oxidation and assimilation of 1,2-propanediol in the facultative methylotroph Pseudomonas AM1. The sites of the lesions in mutant strains are indicated by hatched bars. Mutant PCT29 has low activity of methanol dehydrogenase; mutant PCT76 has no cytochrome $c$; mutants PCT48 and JAB40 are unable to assimilate acetyl-CoA into cell material in the absence of added glyoxylate; mutant JAB21 lacks pyruvate dehydrogenase; mutant JAB10 lacks 2-oxoglutarate dehydrogenase; mutant JAB30 lacks both pyruvate and 2-oxoglutarate dehydrogenases.

constant $(360 \mathrm{mU})$ the rate of propanediol oxidation was proportional to the concentration of PCT29 extract up to a critical value $(0.6 \mathrm{mg}$ protein) above which further increases had little effect.

\section{DISCUSSION}

Two routes have previously been proposed for the complete microbial oxidation of 1,2-propanediol; both routes involve either hydroxyacetone (acetol) or lactaldehyde, and lactate and pyruvate as intermediates. Pyruvate is assimilated and oxidized by way of carboxylation reactions and the tricarboxylic acid cycle (Tanaka et al., 1975a, b; Nishio et al., 1978; Yagi \& Minoda, 1979; Willetts, 1979). The first oxidation reaction was catalysed by an NAD+-linked propanediol dehydrogenase in two methanol-utilizing bacteria (Nishio et al., 1978) and in a non-methylotrophic soil bacterium (strain SA-1)(Tanaka et al., 1975b). In Flavobacterium sp. NCIB 11171 this first reaction may be catalysed by a propanediol oxidase, and in microaerophilic conditions some propanediol is also metabolized by way of a diol dehydratase rearrangement to propionaldehyde followed by reduction to 1-propanol (Willetts, 1979).

By contrast, none of these three enzymes for initial metabolism of propanediol could be demonstrated in extracts of Pseudomonas AM1, and by contrast with organism PAR (Bellion $\& \mathrm{Wu}, 1978$ ), the pure methanol dehydrogenase from Pseudomonas AM1 does not oxidize 1,2-propanediol. In this facultative methylotroph the first step in the metabolism of propanediol appears to be its oxidation to lactate catalysed by methanol dehydrogenase in the presence of a stimulatory factor. The lactate so produced is oxidized to pyruvate and thence to acetyl-CoA which is assimilated by the unconventional route previously proposed (Salem et al., 1973; Anthony, 1975a; Taylor \& Anthony, 1976; Bolbot \& Anthony, 1980). Figure 3 summarizes the pathway proposed for oxidation and assimilation of 1,2-propanediol in Pseudomonas AM1.

The mechanism of action of the stimulatory factor in apparently altering the substrate specificity of the methanol dehydrogenase is not known. A complicating fact is that two sequential oxidation steps are involved although only propanediol and lactate (not the hypothetical intermediate, lactaldehyde) were ever detected in reaction mixtures. This type of sequential oxidation catalysed by methanol dehydrogenase has already been described; the methanol dehydrogenase is unusual in being able to oxidize methanol to formaldehyde, and also formaldehyde to formate (Heptinstall \& Quayle, 1970; Sperl et al., 1974; Sahm 
et al., 1976); during oxidation of methanol to formate the intermediate formaldehyde is not always detectable (Duine et al., 1978).

The results in Fig. 2 are not consistent with the stimulatory factor being a typical activator, binding reversibly to methanol dehydrogenase and thus enabling it to oxidize propanediol. If a typical activator were involved, then the overall rate should be proportional to the methanol dehydrogenase concentration for all concentrations of stimulatory factor (PCT29 extract), and typical hyperbolic curves would be obtained for plots of rate against concentration of stimulatory factor (PCT29 extract).

The slight transitory oxidation of 1,2-propanediol by pure methanol dehydrogenase (Fig. 1, curve 2) suggested that the stimulatory factor might act by removing (oxidizing) an initial inhibitory product of propanediol oxidation (lactaldehyde), i.e. that the factor might be a lactaldehyde dehydrogenase. However, the unusual shape of the curves and the similarity in the shape of the curves in Fig. $2(a, b)$ perhaps argue against this interpretation. The shape of the curves in Fig. 2(a,b) are more typical of titration curves for only two components in which one component has a very high affinity for the other. The most straightforward explanation for the results in Fig. 2 is that the stimulatory factor (possibly a protein), present in crude extracts, binds tightly to the methanol dehydrogenase conferring on it the capability of oxidizing the novel substrate 1,2-propanediol to lactate. An unequivocal demonstration as to which interpretation of these results is correct must await purification of the stimulatory factor from crude extracts; preliminary attempts to achieve this have so far failed.

The apparent modification of specificity of an enzyme in the presence of a stimulatory factor, as suggested here for methanol dehydrogenase, is almost unprecedented in microbial biochemistry; however, a previous preliminary description of this phenomenon (Cox \& Quayle, 1976b) also involved the same enzyme. In that case pure methanol dehydrogenase failed to oxidize 4-hydroxybutyrate although crude extracts oxidized high concentrations of this substrate when included in the methanol dehydrogenase assay system in the place of methanol. The product of 4-hydroxybutyrate oxidation was not determined. As found in the present work, a mutant lacking methanol dehydrogenase (M15A) failed to grow on 4-hydroxybutyrate, although wild-type bacteria grew slowly on this substrate with a mean doubling time of $15 \mathrm{~h}$. It will clearly be of great interest to determine the nature of the factor(s) modifying the substrate specificity of the methanol dehydrogenase and to investigate further the nature of its mode of action.

We thank the SRC for awarding a CASE studentship (with I.C.I) for this work.

\section{REFERENCES}

ANTHONY, C. (1975a). The biochemistry of methylotrophic micro-organisms. Science Progress, Oxford 61, 167-206.

ANTHONY, C. (1975b). The microbial metabolism of $C_{1}$ compounds: the cytochromes of Pseudomonas AM1. Biochemical Journal 146, 289-298.

Anthony, C. \& Zatman, L. J. (1964). The microbial oxidation of methanol. The methanoloxidising enzyme of Pseudomonas sp. M27. Biochemical Journal 92, 614-621.

ANTHONY, C. \& ZatMAN, L. J. (1965). The microbial oxidation of methanol. The alcohol dehydrogenase of Pseudomonas sp. M27. Biochemical Journal 96, 808-812.

AnTHONY, C. \& ZatMAN, L. J. (1967a). The microbial oxidation of methanol. Purification and properties of the alcohol dehydrogenase of
Pseudomonas sp. M27. Biochemical Journal 104, 953-959.

ANTHONY, C. \& ZatMan, L. J. (1967b). The microbial oxidation of methanol. The prosthetic group of the alcohol dehydrogenase of Pseudomonas sp. M27: a new oxidoreductase prosthetic group. Biochemical Journal 104, 960-969.

Bamforth, C. W. \& QuaYle, J. R. (1978). The dye-linked alcohol dehydrogenase of Rhodopseudomonas acidophila. Comparison with dyelinked methanol dehydrogenases. Biochemical Journal 169, 677-686.

Bellion, E. \& Wu, G. T. S. (1978). Alcohol dehydrogenases from a facultative methylotrophic bacterium. Journal of Bacteriology 135, 251-258.

Bentley, R., Sweeley, C. C., Makita, M. \& Wells, W. W. (1963). Gas chromatography of 
sugars and other polyhydroxy compounds. Biochemical and Biophysical Research Communications 11, 14-18.

BERGMEYER, H. U. (1974). Methods of Enzymatic Analysis, 2nd edn, p. 1464. Edited by H. U. Bergmeyer. London: Academic Press.

Bolbot, J. A. \& ANTHONY, C. (1980). The metabolism of pyruvate by the facultative methylotroph Pseudomonas AM1. Journal of General Microbiology 120, 233-244.

Cox, R. B. \& QuAYLE, J. R. (1976a). Synthesis and hydrolysis of malyl-coenzyme A by Pseudomonas AM1: an apparent malate synthase activity. Journal of General Microbiology 95, 121-133.

Cox, R. B. \& QuAYLE, J. R. (1976b). The growth of $P$ seudomonas AM1 on 4-hydroxybutyrate. Journal of General Microbiology 97, 137-139.

Duine, J. A., Frank, J. \& Westerlng, J. (1978). Purification and properties of methanol dehydrogenase from Hyphomicrobium X. Biochimica et biophysica acta 524, 277-237.

Dunstan, P. M., Anthony, C. \& Drabble, W. T. (1972a). Microbial metabolism of $C_{1}$ and $C_{8}$ compounds. The involvement of glycollate in the metabolism of ethanol and of acetate by Pseudomonas AM1. Biochemical Journal 128, 99-106.

Dunstan, P. M., Anthony, C. \& Drabble, W. T. $(1972 b)$. Microbial metabolism of $C_{1}$ and $C_{2}$ compounds. The role of glyoxylate, glycollate and acetate in the growth of Pseudomonas AM1 on ethanol and on $C_{1}$ compounds. Biochemical Journal 128, 107-115.

Heptinstall, J. \& Quayle, J. R. (1970). Pathways leading to and from serine during growth of Pseudomonas AM1 on $C_{1}$ compounds or succinate. Biochemical Journal 117, 563-572.

Maclennan, D. G., Ousby, J. C., Vasey, R. B. \& Corron, N. T. (1971). The influence of dissolved oxygen on Pseudomonas AM1 grown on methanol in continuous culture. Journal of General Microbiology 69, 395-404.

Nishio, N., Kawagishr, T., Matsuno, R. \& KAMIKuBO, T. (1978). Metabolism of 1,2propanediol by methanol-utilising bacteria and some properties of 1,2-propanediol dehydrogenating enzyme. Agricultural and Biological Chemistry 42, 1095-1100.

SAFM, H., Cox, R. B. \& Quayle, J. R. (1976). Metabolism of methanol by Rhodopseudomonas acidophila. Journal of General Microbiology 94, 313-322.

Salem, A. R., Wagner, C., Hacking, A. J. \& QUAYLE, J. R. (1973). The metabolism of lactate and pyruvate by Pseudomonas AM1. Journal of General Microbiology 76, 375-388.

Salem, A. R., Hacking, A. J. \& QuaYle, J. R. (1974). Lack of malyl-CoA lyase in a mutant of Pseudomonas AM1. Journal of General Microbiology 81, 525-527.

SATO, K. (1978). Bacteriochlorophyll formation by facultative methylotrophs, Protaminobacter ruber and Pseudomonas AM1. FEBS Letters 85, 207-210.

SperL, G. T., Forrest, H. S. \& Gibson, D. T. (1974). Substrate specificity of the purified primary alcohol dehydrogenases from methanoloxidising bacteria. Journal of Bacteriology 118, 541-550.

Tanaka, Y., Fujn, K., Tanaka, A. \& Fukui, S. (1975a). Metabolism of 1,2-propanediol in a soil bacterium. Journal of Fermentation Technology 53, 354-362.

Tanaka, Y., Fum, K., Tanaka, A. \& FukUI, S. (1975b). Properties of 1,2-propanediol-dehydrogenating enzyme from a 1,2-propanediol-utilising soil bacterium. Journal of Fermentation Technology 53, 566-568.

TAYLoR, I. J. \& ANTHONY, C. (1976). Acetyl-CoA production and utilization during growth of the facultative methylotroph Pseudomonas AM1 on ethanol, malonate and 3-hydroxybutyrate. Journal of General Microbiology 95, 134-143.

Toraya, T., Yongsmith, B., Honda, S., Tanaka, A. \& Fukur, S. (1976). Production of vitamin $B_{12}$ by a methanol-utilising bacterium. Journal of Fermentation Technology 54, 102-108.

Toraya, T., Krodel, E., Mildvan, A. S. \& Abeles, R. H. (1979). Role of peripheral side chains of vitamin $B_{12}$ coenzymes in the reaction catalysed by dioldehydrase. Biochemistry 18, 417-426.

WilletTs, A. (1979). Bacterial metabolism of propane-1,2-diol. Biochimica et biophysica acta 588, 302-309.

YaGI, O. \& MnNODA, Y. (1979). Lactic acid production from 1,2-propanediol by jar culture and resting cells of Arthrobacter oxydans. Agricultural and Biological Chemistry 43, 571-575. 